\title{
Mortality from cancer in Mexico: 2015 update
}

\author{
Fernando Aldaco-Sarvide ${ }^{1 *}$, Perla Pérez-Pérez ${ }^{1}$, Guadalupe Cervantes-Sánchez ${ }^{2}$, Laura Torrecillas-Torres ${ }^{1}$, \\ Aura Argentina Erazo-Valle-Solís ${ }^{3}$, Paula Cabrera- Galeana ${ }^{4}$, Daniel Motola-Kuba ${ }^{5}$, Pablo Anaya ${ }^{6}$, Samuel \\ Rivera-Rivera ${ }^{7}$ and Eduardo Cárdenas-Cárdenas ${ }^{1}$ \\ ${ }^{1}$ Department of Medical Oncology staff physician; ${ }^{2} \mathrm{Head}$ of the Department of Oncology; ${ }^{3} \mathrm{Head}$ of the Department of Teaching and Research, \\ Centro Médico Nacional 20 de Noviembre, ISSSTE; ${ }^{4}$ Department of Medical Oncology for Breast Cancer staff physician, Instituto Nacional de \\ Cancerología; ${ }^{5}$ Centro Oncológico Médica Sur staff physician; ${ }^{6} \mathrm{Health}$ Economist-RWI principal Quintiles IMS; ${ }^{7} \mathrm{Head}$ of the Department of Medical \\ Oncology, Centro Médico Nacional SXXI, IMSS, Ciudad de México, Mexico
}

\begin{abstract}
Introduction: Cancer is one of the leading causes of mortality in México and is expected to rise in the next years mostly because of an aging population. Nevertheless, only a few comprehensive studies of cancer mortality have been published recently. Objective: Provide an update of the cancer mortality in México. Material y methods: We analyzed official death certification using data-base from Instituto Nacional Estadística y Geografía (INEGI) and population trends from Consejo Nacional de Población (CONAPO). Results: There were 85,201 deaths from cancer in México in 2015 with an overall estimated rate 70.5/105 (men 70.6/105 and women 70.1/105). From 2010 to 2015, overall cancer mortality estimated rate has increased by 5.4\% from 66.6 to 70.5/105. The first five types of cancer cause of death were: prostate 10.9/105, breast 10.1/105, cervical cancer 6.4/105, lung 5.7/105 and liver 5.2/105. Death rates for lung and cervical cancers have decreased since year 2000. Conclusions: Cancer mortality rates are still increasing in México, although, some types of cancer rates are beginning to stabilize. Prostate cancer is the leading cause of cancer death in México.
\end{abstract}

Key words: Cancer. Mexico. Mortality

\section{Correspondence:}

F. Aldaco-Sarvide

E-mail: fernando@aldaco.net
Available online: 01-04-2019 Gac Mex Oncol. 2018;17:24-30 www.gamo-smeo.com 1665-9201/@2018 Sociedad Mexicana de Oncología. Published by Permanyer México. This is an Open Access article under the terms of the CC BY-NC-ND license (http://creativecommons.org/licenses/by-nc-nd/4.0/). 


\section{Introduction}

Currently, cancer is the third cause of mortality in Mexico, with $12.9 \%$ of all cases. According to National Institute of Statistics, Geography and Informatics (INEGI - Instituto Nacional de Estadística, Geografía e Informática) data, in the year 2015, a total of 655,688 people died; the 3 main causes of death were: diabetes mellitus complications $(98,521)$, ischemic heart disease complications $(88,144)$ and cancer $(85,201)^{1}$.

Cancer mortality in Mexico shows a sustained increase over the last decades ${ }^{2,3}$; between the years 2000 and $2015,1,129,703$ people died from cancer ${ }^{1}$. Available information to assess cancer prevalence/incidence in our country is difficult to interpret, since although there are mortality-related reports available, updated information relative to the number of new cases and prevalence is limited ${ }^{4}$.

Information limitations only allow developing actions based on external systems such as the one known as GLOBOCAN, published by the International Agency for Research on Cancer ${ }^{5}$.

Analysis of the cancer-associated mortality trend is complex, since a heterogeneous group of diseases that epidemiologically behave in different forms are encompassed by the same diagnosis ${ }^{6}$. A clear example is the decrease in cervical cancer-associated mortality, whereas in breast and prostate tumors a mortality increase is observed ${ }^{2,3,7}$. Any analysis of the cancer situation should contemplate a general outlook including an updated and reliable registry ${ }^{8-10}$.

This work aims to provide updated information with the purpose to understand the current state, assess tendencies and facilitate actions in matters of public health for the years to follow.

\section{Material and method}

The interactive database on cancer mortality according to the International Classification of Diseases ICD$10 / 2^{11}$, available at the INEGI website, was reviewed for the years 2000 to $2015^{1}$. The analyzed variables by means of descriptive statistics were: year of registration, type of cancer (ICD-10/2), age, gender, permanent address, place of decease and health system affiliation. The gross mortality rate per $100,000\left(10^{5}\right)$ was calculated according to National Population Council (CONAPO - Consejo Nacional de Población) ${ }^{12}$ population projections between 2011 and 2015 .

All data are recorded with regard to the deceased individual permanent address; however, since medical care institutions operate by means of patient referral to different national or regional referral centers throughout the country, there might be discrepancy between the place where the decease is recorded and the individual's permanent address. For this reason, performing an exploratory was decided evaluating the entire country. A previously-published database was used to make comparisons over the past decade ${ }^{2}$. To calculate mortality at the Institute of Security and Social Services of State Workers (ISSSTE - Instituto de Seguridad y Servicios Sociales de los Trabajadores del Estado), at the Mexican Institute of Social Security (IMSS - Instituto Mexicano del Seguro Social), Mexican Petroleum (PEMEX - Petroleos Mexicanos), the Secretary of National Defense SEDENA - Secretaría de la Defensa Nacional) and People's Insurance (Seguro Popular), the affiliated population database, which is available at each institution's website and at INEGI, was reviewed.

\section{Results}

\section{General mortality in the country and by states}

Cancer mortality in Mexico in the year 2015 was 85,201 cases. From all deaths, $54.2 \%$ occurred at home, $36.4 \%$ at a public sector hospital and $4.8 \%$ in a private health institution. Of these events, $48.9 \%$ occurred in men versus $51.1 \%$ in women. The mortality rate per 105 population in the country for both genders is 70.4: in women it is 70.1 and in men 70.6.

The 5 States with the highest mortality by number were: State of Mexico 9,857, Mexico City 8,598, Veracruz 6,346, Jalisco 5,772 and Nuevo León 3,953. The 5 states with the highest rates were: Mexico City with 97.1, Sonora 89.1, Veracruz 78.9, Sinaloa 78.6 and Chihuahua 78.5 . Mortality distribution by State for the year 2015 can be observed in table 1 .

The exploratory analysis according to the usual place of residence and place of decease could only be determined in Mexico City as a place of interest, where $24 \%$ of deaths were observed to correspond to residents from other States (little more than two third parts were State of Mexico residents).

\section{Mortality by age groups}

Ninety percent of cancer-related deaths occur in the population aged 40 years or older, which represents only $30 \%$ of the country's total population; $65 \%$ of deaths occurred in people aged 60 years or older, which represents $9.7 \%$ of the population. 
Table 1. Overall mortality by State and 2000-2015 annual rate

\begin{tabular}{|c|c|c|c|c|c|c|}
\hline & \multicolumn{2}{|c|}{2015} & \multirow{2}{*}{$\begin{array}{c}2010 \\
\text { Rate } 10^{5}\end{array}$} & \multirow{2}{*}{$\begin{array}{c}2000 \\
\text { Rate } 10^{5}\end{array}$} & $2000-2015$ & $2010-2015$ \\
\hline & Deaths & Rate $10^{5}$ & & & \multicolumn{2}{|c|}{ Yearly change in rate $(\%)$} \\
\hline National & 85,201 & 70.4 & 66.5 & 59.3 & +1.24 & +1.16 \\
\hline 1. Mexico City & 8,598 & 97.1 & 88.1 & 75.2 & +1.94 & +2.04 \\
\hline 2. Sonora & 2,613 & 89.1 & 83.1 & 77.1 & +1.03 & +1.44 \\
\hline 3. Veracruz & 6,346 & 78.9 & 74.4 & 64.6 & +1.47 & +1.2 \\
\hline 4. Sinaloa & 2,344 & 78.6 & 77.3 & 70 & +0.81 & +0.32 \\
\hline 5. Chihuahua & 2,910 & 78.4 & 75.1 & 69.1 & +0.89 & +0.92 \\
\hline 6. Nuevo León & 3,953 & 77.8 & 72.1 & 68.9 & +0.86 & +1.58 \\
\hline 7. Coahuila & 2,260 & 77.3 & 66.3 & 69.1 & +0.78 & +3.3 \\
\hline 8. Nayarit & 945 & 77.4 & 75 & 73.2 & +0.38 & +0.64 \\
\hline 9. Colima & 547 & 75.6 & 78.3 & 63.7 & +1.33 & -0.6 \\
\hline 10. Morelos & 1,438 & 74.8 & 73.2 & 62.9 & +1.26 & +0.42 \\
\hline 11. Michoacán & 3,419 & 74.8 & 70.5 & 64.2 & +1.06 & +1.2 \\
\hline 12. Tamaulipas & 2,607 & 73.6 & 72.5 & 53.9 & +2.43 & +0.3 \\
\hline 13. Jalisco & 5,772 & 72.7 & 72.4 & 70.2 & +0.23 & +0.08 \\
\hline 14. Zacatecas & 1,127 & 71.1 & 68.2 & 64 & +0.73 & +0.84 \\
\hline 15. Оахаса & 2,828 & 70.5 & 63.9 & 52.7 & +2.24 & +2.06 \\
\hline 16. San Luis Potosí & 1,905 & 69.2 & 66.2 & 59.5 & +1.08 & +0.81 \\
\hline 17. Yucatán & 1,459 & 69.1 & 66.1 & 63.8 & +0.55 & +0.9 \\
\hline 18. Baja California & 2,352 & 67.5 & 62.9 & 54.7 & +1.56 & +1.46 \\
\hline 19. Aguascalientes & 857 & 66.5 & 60.5 & 52.9 & +1.71 & +1.81 \\
\hline 20. Hidalgo & 1,858 & 64.7 & 60.7 & 47.6 & +2.39 & +1.3 \\
\hline 21. Baja California Sur & 491 & 64.3 & 61 & 66.7 & -0.24 & +1 \\
\hline 22. Durango & 1,131 & 64 & 61.8 & 55.6 & +1 & +0.7 \\
\hline 23. Puebla & 3,928 & 63.4 & 56.3 & 50.1 & +1.76 & +2.52 \\
\hline 24. Chiapas & 3,254 & 61.9 & 57.3 & 49.6 & +1.64 & +1.6 \\
\hline 25. Guanajuato & 3,560 & 61.2 & 57.7 & 52.9 & +1.04 & +1.2 \\
\hline 26. Tabasco & 1,458 & 61.2 & 69.6 & 49.3 & +1.6 & -2.4 \\
\hline 27. Campeche & 552 & 60.8 & 59.2 & 51.4 & +1.21 & +0.54 \\
\hline 28. Querétaro & 1,180 & 59 & 53.9 & 45.3 & +2.01 & +1.88 \\
\hline 29. State of Mexico & 9,857 & 58.4 & 42.7 & 33.1 & +5.09 & +7.34 \\
\hline 30. Guerrero & 2,073 & 58.2 & 52.1 & 29.8 & +6.35 & +2.34 \\
\hline 31. Tlaxcala & 725 & 57 & 47.1 & 34.3 & +4.04 & +4.2 \\
\hline 32. Quintana Roo & 751 & 47.8 & 35 & 24.8 & +6.18 & +7.3 \\
\hline
\end{tabular}

The mortality rate per $10^{5}$ population and age group 49 years, $53.77 ; 50$ to 59 years, $131.1 ; 60$ to 69 years, in 2015 was: 0 to 9 years, 5.23; 10 to 19 years, 6.38; 291; 70 to 79 years, 574 and 80 years or older, 954 . 20 to 29 years, 9.2; 30 to 39 years, 20.33; 40 to The analysis of years 2010 vs. 2015 only established 
Table 2. Mortality and specific rate by year and cancer type

\begin{tabular}{|c|c|c|c|c|c|c|c|c|}
\hline \multirow[t]{2}{*}{ Cancer } & \multicolumn{2}{|c|}{2015} & \multicolumn{2}{|c|}{2010} & \multicolumn{2}{|c|}{2005} & \multicolumn{2}{|c|}{2000} \\
\hline & Deaths & Rate & Deaths & Rate & Deaths & Rate & Deaths & Rate \\
\hline $\begin{array}{l}\text { Overall } \\
\text { - Women } \\
\text { - Men }\end{array}$ & $\begin{array}{l}85,201 \\
43,485 \\
41,716\end{array}$ & $\begin{array}{l}70.4 \\
70.1 \\
70.6\end{array}$ & $\begin{array}{l}74,685 \\
38,034 \\
36,646\end{array}$ & $\begin{array}{l}66.6 \\
66.1 \\
66.7\end{array}$ & $\begin{array}{l}66,464 \\
38,818 \\
32,640\end{array}$ & $\begin{array}{l}64.3 \\
63.7 \\
64.9\end{array}$ & $\begin{array}{l}57,784 \\
29,940 \\
27,841\end{array}$ & $\begin{array}{c}59.3 \\
60 \\
58.5\end{array}$ \\
\hline Lung & 6,903 & 5.7 & 6,795 & 6 & 7,048 & 6.8 & 6,274 & 6.4 \\
\hline Prostate & 6,447 & 10.9 & 5,508 & 10 & 4,800 & 9.5 & 3,852 & 8 \\
\hline Liver and bile ducts & 6,333 & 5.2 & 5,393 & 4.8 & 4,849 & 4.6 & 4,186 & 4.2 \\
\hline Breast & 6,304 & 10.1 & 5,094 & 9.1 & 4,264 & 8.4 & 3,503 & 7 \\
\hline Gastric & 6,065 & 5 & 5,599 & 4.9 & 5,336 & 5.1 & 5,009 & 5.1 \\
\hline Colorectal & 5,853 & 4.8 & 4,056 & 3.6 & 3,367 & 3.2 & 2,622 & 2.6 \\
\hline Leukemia & 4,365 & 3.6 & 3,953 & 3.5 & 3,733 & 3.6 & 3,301 & 3.3 \\
\hline Pancreas & 4,184 & 3.4 & 3,631 & 3.2 & 3,199 & 3 & 2,669 & 2.7 \\
\hline Cervical & 4,009 & 6.4 & 3,952 & 6.9 & 4,227 & 8 & 4,620 & 9.1 \\
\hline Ovary & 2,379 & 3.8 & 1,845 & 3.2 & 1,493 & 2.8 & 1,156 & 2.3 \\
\hline Non-Hodgkin lymphoma & 2,523 & 2 & 2,140 & 1.9 & 1,964 & 1.9 & 1,568 & 1.6 \\
\hline Central nervous system & 2,442 & 2 & 2,021 & 1.7 & 1,799 & 1.7 & 1,431 & 1.4 \\
\hline Renal & 2,245 & 1.9 & 1,859 & 1.6 & 1,510 & 1.4 & 1,772 & 1.8 \\
\hline Melanoma/skin & 1,763 & 1.4 & 1,467 & 1.3 & 1,238 & 1.1 & 1,071 & 1 \\
\hline Lip/mouth/pharynx & 1,196 & 0.9 & 1,037 & 0.9 & 960 & 0.9 & 773 & 0.8 \\
\hline Myeloma multiple & 1,135 & 0.9 & 899 & 0.8 & 785 & 0.7 & 610 & 0.6 \\
\hline Esophagus & 1,093 & 0.9 & 955 & 0.8 & 859 & 0.8 & 770 & 0.7 \\
\hline Bladder & 1,053 & 0.8 & 919 & 0.8 & 747 & 0.7 & 618 & 0.6 \\
\hline Larynx & 820 & 0.6 & 791 & 0.7 & 771 & 0.7 & 848 & 0.8 \\
\hline Endometrium & 680 & 1 & 418 & 0.3 & 286 & 0.2 & 201 & 0.4 \\
\hline Testicle & 534 & 0.4 & 416 & 0.7 & 360 & 0.7 & 311 & 0.6 \\
\hline Not specified/uncertain & 8,421 & - & 7,701 & - & 5,764 & - & 4,955 & - \\
\hline Others & 10,141 & - & 8,236 & - & 7,059 & - & 5,664 & - \\
\hline
\end{tabular}

an increase higher than $10 \%$ in the 50 to 59 years' group, with the rate rising from 113 to 131 .

\section{Mortality in the country}

The main causes of cancer-related death according to the number of events are: lung 6,903, prostate 6,447, liver and intrahepatic bile ducts (LIHBD) 6,333, breast 6,304 and gastric 6,065 .

The mortality rates $\left(10^{5}\right)$ of the 5 most common neoplasms are: prostate 10.7 , breast 10.1 , cervix 6.4 , lung 5.7 and LIHBD 5.2. The distribution of the 21 most common causes of cancer-related death in Mexico in the year 2015 and a comparison with previous years can be observed in table 2 .

\section{Mortality by health service provider}

The reported mortality among affiliates to the main health institutions by number and rate is: PEMEX 1,055, rate 138 per $10^{5}$; SEDENA 684, rate 82.2 per $10^{5}$; ISSSTE 7,902, rate 60.8 per $10^{5}$; IMSS 35,055 , rate 56.3 per 105; and Seguro popular 21,244, rate 38.6 per $10^{5}$. A total of 10,119 deaths were reported (accounting for $11.8 \%$ of deaths) that had no health services provider (in 2010 it was $21 \%$ ). 
Table 3. Overall mortality and rate by gender in 2015

\begin{tabular}{|c|c|c|c|c|c|}
\hline \multicolumn{3}{|c|}{ Women } & \multicolumn{3}{|c|}{ Men } \\
\hline National & Cases & $\%$ & National & Cases & $\%$ \\
\hline & 43,485 & 51.1 & & 41,716 & 48.9 \\
\hline Specific & & 14.3 & Specific & & \\
\hline 1. Breast & 6,273 & 9.2 & 1. Prostate & 6,447 & 15.4 \\
\hline 2. Uterine cervix & 4,009 & 7.8 & 2. Lung & 4,330 & 10.3 \\
\hline 3. Liver & 3,245 & 6.4 & 3. Stomach & 3,262 & 7.8 \\
\hline 4. Stomach & 2,803 & 6.9 & 4. Liver & 3,088 & 7.4 \\
\hline 5. Lung & 2,573 & 6.3 & 5. Colorectal & 3,075 & 7.3 \\
\hline 6. Colorectal & 2,778 & 5.4 & 6. Leukemia & 2,367 & 5.6 \\
\hline 7. Ovary & 2,379 & 5.1 & 7 Pancreas & 1,953 & 4.6 \\
\hline 8. Pancreas & 2,231 & 4.5 & 8. Non-Hodgkin lymphoma & 1,402 & 3.3 \\
\hline 9. Leukemia & 1,996 & 2.5 & 9. Esophagus & 845 & 2 \\
\hline 10. Non-Hodgkin lymphoma & 1,121 & & 10. Bladder & 727 & 1.7 \\
\hline
\end{tabular}

The 5 main causes of death at each institution are: IMSS, lung cancer $8.6 \%$, breast $7.7 \%$, prostate $7.4 \%$, colorectal $7.3 \%$ and LIHBD 6.7\%; ISSSTE, prostate $8.4 \%$, breast $8.2 \%$, LIHBD $8.2 \%$, lung $7.8 \%$ and colorectal $6.8 \%$; Seguro popular, breast $7.7 \%$, LIHBD $7.1 \%$, stomach $7.1 \%$, lung $7 \%$ and uterine cervix $6.9 \%$; PEMEX, LIHBD $10.2 \%$, prostate $9.3 \%$, lung $8.2 \%$, breast $7.3 \%$ and colorectal 6.8\%; and SEDENA, LIHBD 8.3\%, stomach $7.1 \%$, colorectal $7 \%$, leukemia $7 \%$ and prostate $6.4 \%$.

\section{Specific mortality}

Next, the 10 most common causes of cancer-related death are listed by rate and State of the Republic, as well as in the pediatric population. The number of cases and the percentage of mortality can be observed grouped by gender in table 3 .

- Lung cancer. The States with the highest mortality rate are Sinaloa with 11.3; Sonora, 10.8; Nayarit, 9.2; Chihuahua, 8.9, and Nuevo León, 8.1.

- Prostate cancer. The States with the highest mortality are: Nayarit, 20; Michoacán, 15.6; Sinaloa, 15.2; Mexico City, 14.9, and Colima, 14.2.

- LIHBD cancer. The States with the highest mortality are: Veracruz, 10; Yucatán, 7.2; Campeche, 7: Oaxaca, 6.6; Mexico City, 6.5, and Tamaulipas-Chiapas, 6.4.

- Breast cancer. The States with the highest mortality are: Mexico City, 16; Sonora, 16; Nuevo León, 15.2; Coahuila, 14.2, and Chihuahua, 14.
- Gastric cancer. The States with the highest mortality are: Chiapas, 8.1; Oaxaca, 7.3; Mexico City, 6.8; Guerrero, 6.6, and Morelos, 6.5.

- Colorectal cancer: The States with the highest mortality are: Chiapas, 8.9; Chihuahua, 7.1; Mexico City, 7.1; Sonora, 6.6, and Baja California, 6.4.

- Leukemia. The States with the highest mortality are: Campeche, 5.3: Mexico City, 4.5; Chiapas, 4.3; Colima, 4.3, and Oaxaca, 4.2.

- Pancreatic cancer. The States with the highest mortality are: Mexico City, 5.4; Michoacán, 4.4; Sonora, 4.3; Sinaloa, 4.2, and Aguascalientes, 4.3.

- Cervical cancer. The States with the highest mortality are: Colima, 10.3; Veracruz, 8.8; Chiapas, 8.7; Yucatán, 8.5, and Nayarit-Morelos-Oaxaca with 8.1.

- Pediatric population. In the 19-year old and younger population there was a total of 2,599 cancer-related deaths in the year 2015, with a rate of 5.8 per $10^{5}$, which corresponds to $5.7 \%$ of all deaths for any cause in population younger than 20 years, or $3 \%$ of cancer-related deaths among all population groups. Out of total cases, $58.5 \%$ corresponds to boys and $41.5 \%$ to girls. Grouped by age, the cases are: younger than one year, 135 (rate 6 per $10^{5}$ ); 1 to 4 years, 478 (rate 4.3 per $10^{5}$ ); 5 to 9 years, 554 (rate 4.9 per $10^{5}$ ); 10 to 14 years, 581 (rate 5.1 per $10^{5}$ ) and 15 to 19 years, 851 (rate 7.6 per 105). The 5 States with the highest number of cases are: State of Mexico, 363; Veracruz, 189; Jalisco, 174; Chiapas, 160; and Mexico City, 140. The 3 main causes of death are: 
hematological neoplasms, 1,320 (acute lymphoblastic leukemia, 836, and acute myeloblastic leukemia, 173); malignant tumors of the eye and central nervous system, 358, and malignant tumors of the bone/ cartilage, 188.

\section{Discussion}

The rate of cancer mortality has maintained a sustained increase over the past 15 years, with an apparent trend for the intensity observed in past decades to be reduced. Between the years 2000 and 2015, the mortality rate increased at an annualized average of $1.24 \%$, which is lower than the figures observed between 1995 and 2000; these findings are consistent with other studies ${ }^{2,3}$.

Apparently, the country is entering into a plateau phase, which could coincide with similar situations in other countries of the region ${ }^{13}$. However, when the population dynamics is assessed, and considering population aging during the next decades, it is a worrying fact that two third parts of deaths occur in the population group aged $>60$ years, which corresponds to less than $10 \%$ of the population. According to CONAPO, there are more than 80 million Mexicans younger than 40 years, which is something to consider with future perspectives ${ }^{14}$. In a favorable scenario, the overall mortality rate will remain without significant changes, but on the other hand, there is a probable negative scenario, where the number of cases and the mortality rate would be substantially increased.

An interesting case is Mexico City. If total death rate of people with usual residence in Mexico City is calculated, a rate of 97.1 per $10^{5}$ is reported; however, if the rate is calculated for total deaths including residents and non-usual residents, the rate increases to 127 per $10^{5}$; this is due to the fact that $24.5 \%$ of deaths correspond to population with usual residence in other States of the Republic (mainly in the State of Mexico), which would explain the discrepancy with a study previously published by us, where we reported a rate of 117 per $10^{5}$ population in $2000^{2}$.

Ordered by frequency, the main causes of cancer-related death according to the number of cases remain relatively unchanged; however, a substantial increase in the number and rate of gastrointestinal tract tumors can be clearly observed, which, associated with a stabilization or decrease in mortality from other tumors enables establishing the hypothesis that these tumors will have a preponderant place in the years to come $^{16,16}$.
In spite of being one of the main causes of neoplasm-associated death, the decrease in the mortality rate from cervical cancer is confirmed, with almost one third reduction (from 9.1 per $10^{5}$ population in 2000 to 6.45 per $10^{5}$ in 2015), and this trend is to be expected to continue over the years if we consider the relatively recent introduction of the human papilloma virus vaccine in the country. Lung cancer shows a clear tendency towards a plateau with regard to mortality, with a reduction of $11 \%$ in the mortality rate between 2000 and 2015; however, the sub-analysis by gender clearly demonstrates that mortality has not increased in men, while, in women, the increase in the number of cases and mortality rate is maintained with a constant increase. When differences between both genders and evolution over time are analyzed, men can be observed to show an increase of $1.2 \%$ between 1998 and 2015 versus $30 \%$ in women in the same time period. In contrast with the study published by Bray ${ }^{15}$, who observed a reduction in death from lung cancer in women, we detected an increase in the mortality rate; the discrepancy might be due to the fact that Bray's study used projections of the GLBOCAN 2012 database.

The biggest current and future challenge is observed in breast cancer and prostate-associated mortality, owing to the substantial increases in the mortality rate over the last 15 years. For both cases, more than two third parts of deaths occur in the population older than 60 years; in older women, the breast cancer mortality rate is multiplied by 7 , whereas in men, it is multiplied by 35 in the case of prostate cancer, which gives an idea of the evolution these pathologies will experience on the mid-term. In this sense, several studies have estimated a mortality increase in the Latin America region for the next decades ${ }^{17,18}$. There is clearly a need for plans of action to be intensified and improved with the purpose to contain the health and economic consequences that are going to occur in a short period of time.

The main limitations of the study are, on one hand, the fact of obtaining information from death records, which in an undetermined number were potentially certified by people who were foreign to patients' diagnosis and treatment and, on the other hand, the fact of not having reliable national records available with regard to cancer incidence and prevalence. Therefore, global interpretation of the information is limited.

The dynamics of the disease and the population transition enable seeing that we are entering a cancer epidemiological transition stage, which hypothetically will occur in a first phase characterized by a discrete 
increase in the mortality rate and, perhaps, a small plateau phase, to subsequently enter in an accelerated growth phase, associated with a differentiation for each one of the different types of tumors. There is an urgent need to increase health investment and to implement better programs for early detection, warrant access to new forms of treatment, improve the available structure and promote the training of human resources focused on cancer care. The main limitation and the risk we will be facing is the procurement and assignment of economic resources ${ }^{19}$ to the different public health systems of the country.

\section{Conclusions}

The rate of cancer mortality in Mexico has maintained a sustained increase over the last years, with a heterogeneous evolution being observed between the different types of tumors, and with prostate cancer currently being the leading cause of cancer-related death.

\section{Conflict of interests}

The authors of this work declare not having any conflicts of interests.

\section{References}

1. Instituto Nacional de Estadística y Geografía Internet México; 2017 fecha de acceso: 12/01/2017. Disponible en: http://www.inegi.org.mx
2. Aldaco SF, Pérez PP, Cervantes SG, et al. Mortalidad por cáncer en México 2000-2010: el recuento de los daños. GAMO. 2012;11(6):371-9.

3. González RA, Gonzales AR, Sánchez FA, et al. Tendencia de mortalidad por cáncer en México: 1990-2012. Evid Med Invest Salud. 2015;8(1):5-15.

4. Compendio del Registro Histopatológico de las Neoplasias Maligna en México. México: Secretaría de Salud. Dirección General de Epidemiología; 2011.

5. Ferlay J, Soerjomataram I, Ervik M, et al. GLOBOCAN 2012 v1.0, Cancer Incidence and Mortality Worldwide: IARC CancerBase No. 11 Internet. Lyon, France: International Agency for Research on Cancer; 2013 fecha de acceso: 13/02/2017. Disponible en: http://globocan.iarc.fr

6. Song Q, Merajver SD, Li JZ. Cancer classification in the genomic era: five contemporary problems. Hum Genomics. 2015;9(1):27-35.

7. Palacio-Mejía LS, Lazcano-Ponce E, Allen-Leigh B, et al. Regional differences in breast and cervical cancer mortality in Mexico between 1979-2006. Salud Publica Mex. 2009;51(Suppl 2):s208-19.

8. Reynoso-Noverón N, Meneses-García A, Erazo-Valle A, et al. Challenges in the development and implementation of the National Comprehensive Cancer Control Program in Mexico. Salud Publica Mex. 2016:58(2):325-33.

9. Leal YA, Fernández-Garrote LM, Mohar-Betancourt A, et al. The importance of registries in cancer control. Salud Publica Mex. 2016;58(2):309-16.

10. Gutiérrez-Delgado C, Armas-Texta D, Reynoso-Noverón N, et al. Estimating the indirect costs associated with the expected number of cancer cases in Mexico by 2020. Salud Publica Mex. 2016;58(2):228-36.

11. Organización Mundial de la Salud. Clasificación internacional de enfermedades. Décima revisión. Ginebra: OMS; 1994.

12. Consejo Nacional de Población. Proyecciones de población (CONAPO) de la República Mexicana, 1990-2010 Internet. México, D.F.:2012 fecha de acceso: enero 2012. Disponible en: http://www.conapo.gob.mxs

13. Piñeros $M$, Gamboa $O$, Hernández-Suárez $G$, et al. Patterns and trends in cancer mortality in Colombia 1984-2008. Cancer Epidemiol. 2013; 37(3):233-9.

14. García-Junco Machado D. La transformación del sistema de salud y el Seguro Popular. Gac Med Mex. 2012;148(6):518-24.

15. Verastegui E, Mohar A. Colorectal cancer in Mexico: should a middle income country invest in screening or in treatment? Eur J Health Econ. 2010;10(Suppl 1):S107-14.

16. Villalobos-Pérez JJ, Bourlon BT, Loeza del castillo A, et al. Variaciones en la frecuencia de cáncer del aparato digestivo en el transcurso de 35 años en cuatro instituciones de la Ciudad de México de distinto nivel socioeconómico. GAMO. 2014;150(6):49-57.

17. Bray $F$, Piñeros $M$. Cancer patterns, trends and projections in Latin America and the Caribbean: a global context. Salud Publica Mex. 2016 Apr;58(2):104-17.

18. Curado MP, de Souza DL. Cancer burden in Latin America and the Caribbean. Ann Glob Health. 2014;80(5):370-7.

19. Goss PE, Lee BL, Badovinac-Crnjevic T, et al. Planning cancer control in Latin America and the Caribbean. Lancet Oncol. 2013;14(5):391-436. 